\title{
The effectiveness of a magnetic physical water treatment device on scaling in domestic hot-water storage tanks
}

\author{
C Smith ${ }^{1}$, PP Coetzee ${ }^{2}$ and JP Meyer ${ }^{1 *}$ \\ ${ }^{1}$ Department of Mechanical and Manufacturing Engineering, Rand Afrikaans University, PO Box 524, Auckland Park 2006, \\ Johannesburg, South Africa \\ ${ }^{2}$ Department of Chemistry and Biochemistry, Rand Afrikaans University, PO Box 524, Auckland Park 2006, Johannesburg, \\ South Africa
}

\begin{abstract}
In this paper the effectiveness of a permanent magnet for the prevention of scale was investigated. Experiments were conducted on two electrically heated domestic hot-water storage tanks. Ten experiments were conducted, each over a period of $28 \mathrm{~d}$ in which $8000 \ell$ of water was heated to $75^{\circ} \mathrm{C}$, while the quality of the feed water and mass precipitation of calcium were monitored. In four of the experiments reproducibility was investigated which was found to be good. In the other six experiments the effect of the permanent magnet was evaluated by commuting it between the two storage tanks. It was found that the permanent magnet was effective in suppressing the mass precipitation of scale in all six these experiments.
\end{abstract}

Keywords: physical water treatment, permanent magnet, hot water, storage tanks

\section{Introduction}

Scaling problems in a heating or cooling system can be recognised by one or more of the following symptoms: reduction in heat transfer rate, in which the formation of an insulating deposit on a heat transfer surface significantly reduces the cooling or heating efficiency of the equipment; reduced water flow, which results from a partial or complete blockage of pipelines, condenser tubes, or other openings. Even a small build-up of scale on a heat exchange surface reduces water flow. Scale may continue to build up in boilers until heat transfer is so low that the metal overheats, permitting the tubes to rupture under the operating pressure. Scale is usually found in waterhandling equipment in which water is heated, i.e. hot-water storage tanks, boilers, etc.

The magnitude of this problem may be appreciated by considering that scaling can cause degradation, or complete failure in thermal and hydraulic performance which increases initial and operating costs (Chan and Ghassemi, 1991). In a fairly low-pressure boiler, only $0.6 \mathrm{~mm}$ of calcium sulphate scale on the tubes results in $180^{\circ} \mathrm{C}$ temperature drop. The cost involved due to heat transfer inefficiency and the removal of scale, in Britain alone, is estimated at $£ 1$ billion per annum (Darvill, 1993). Poor conductivity of a $25 \mathrm{~mm}$ thick $\mathrm{CaCO}_{3}$ scale layer can decrease the heat transfer by $95 \%$ (Glater et al., 1980), whereas a $\mathrm{SiO}_{2}$ scale layer $0.5 \mathrm{~mm}$ thick results in a $90 \%$ decrease in heat transfer (Grutsch and McClintock, 1984).

The suggested mechanism by which scaling occurs is as follows: The calcium in the solution, is derived either from dissolution from natural resources, or from chemicals added during water treatment. The concentration of $\mathrm{CO}_{2}$ dissolved in the water determines the dissolution of calcium carbonate. Calcium carbonate becomes less soluble at higher temperatures and on heating, $\mathrm{CO}_{2}$ escapes favouring the bicarbonate decomposition reaction which causes calcium

\footnotetext{
* To whom all correspondence should be addressed.

酉 +2711 489 2607; fax: +271 489 2532; e-mail: jmeyer@up.ac.za Received 4 April 2001; accepted in revised form 31 March 2003.
}

carbonate to precipitate. At a pH value of less than 8.8 , the solubility of calcium carbonate increases with decreasing $\mathrm{pH}$ and decreases with rising temperature. If the $\mathrm{pH}$ is larger than 8.8 , the solubility increases with increasing temperature and $\mathrm{pH}$ (Yacoby, 1995). Pure calcium carbonate is found in three general forms, i.e. vaterite, calcite, and aragonite with calcite being the major constituent in calcium carbonate scale. To try to prevent or minimise the formation of scale, different techniques have been developed. These techniques can be divided into the following groups: chemical, detonation-wave techniques, blow-down, and physical water treatment (PWT).

Since the first physical water treatment patent was registered in 1945 (Vermeiren, 1958), hundreds of these PWT devices have appeared on the market that are reported to reduce scale formation and blow-down requirements without chemical treatment. These devices include those based on permanent magnets, electromagnets, high frequency electric fields, high voltage electrostatic fields, ultrasonic treatment, flow restriction and catalytic conversion.

The efficiency of physical water treatment devices for the prevention of scale is a controversial subject. Busch et al. (1986), for example, surveyed approximately 60 papers on this subject. They have found that many contradictions exist in the claimed effects, and that even when performance is reported to be effective, the results are typically characterised by low reproducibility. Busch et al. (1986) state that "No agreement exists on optimum operating parameters that should be used in the installation of these devices, and in many cases, exact experimental conditions are not given, which makes valid inter-comparison of the results nearly impossible. Finally, many of the theories relating magnetic fields to scale formation involve unsubstantiated, pseudoscientific postulations of strange, mysterious effects of the magnetic field on the structure of water and dissolved minerals. All of these factors have created a great deal of scepticism with regard to this technology." In a review paper by Baker and Judd (1996) it was concluded that at that stage it was still not certain as to whether magnetic suppression of scaling was a bona fide phenomenon.

It is the purpose of this study to evaluate the effectiveness of a permanent magnet, as a physical water treatment device, for the 


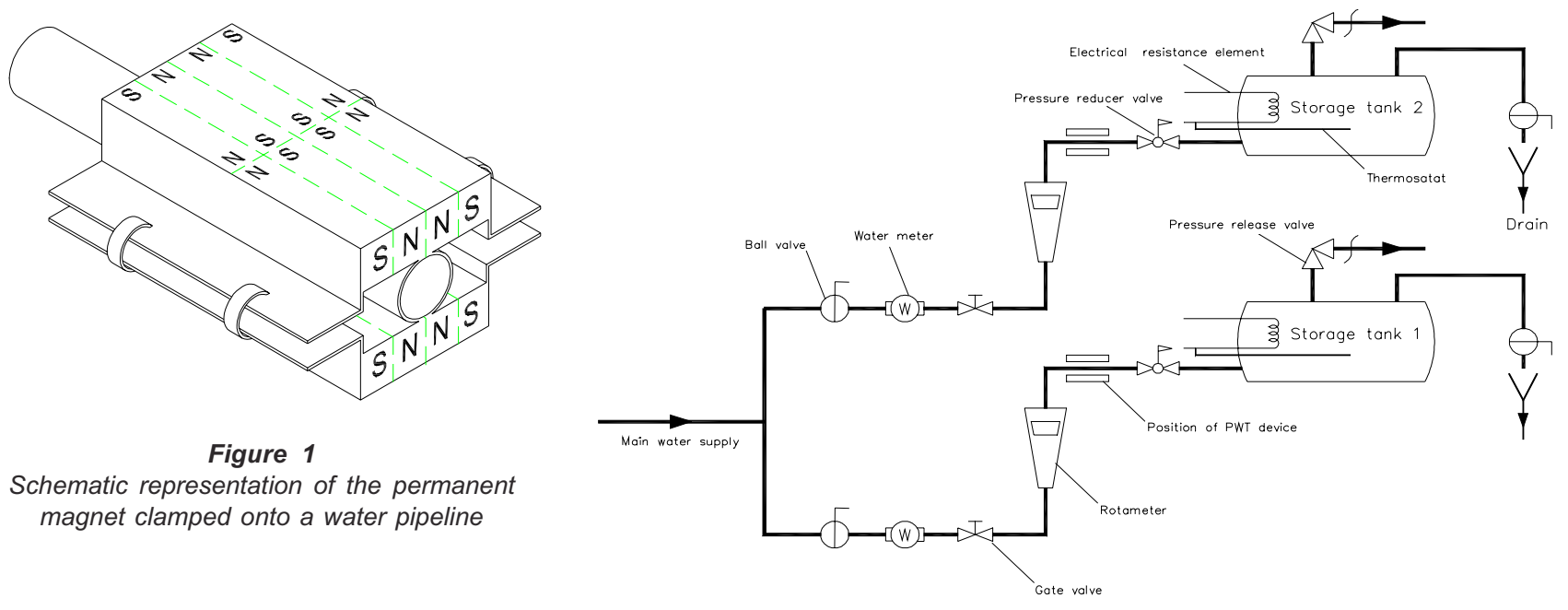

prevention of scale formation in domestic hot-water storage tanks. The permanent magnet used was an arbitrary choice, and is commercially sold as an ENEFLOW ${ }^{\mathrm{TM}} 1000$ Fluid Dynamic Power Cell and is schematically shown in Fig. 1.

\section{Experimental set-up}

The experimental set-up is shown schematically in Fig. 2. It consisted of two domestic, electrically heated, horizontal hot-water storage tanks, connected in parallel. Their measured capacities were 197 litres and 191 litres, respectively, for storage tanks one and two. The inside of the storage tanks was manufactured from mild steel coated with glass enamel. The tanks were insulated with $50 \mathrm{~mm}$ of polyurethane and their standing losses were $2.6 \mathrm{kWh}$ per day. The thermostat setting on both tanks that controlled the electrical current to the resistance elements was adjusted and calibrated to keep the water temperature constant at $75^{\circ} \mathrm{C}$ with an average error of $\pm 2^{\circ} \mathrm{C}$. They were each fitted with electrical resistance elements with measured heating capacities of $2960 \mathrm{~W}$ and $2850 \mathrm{~W}$ each. The resistance elements were manufactured from copper plated with nickel. The average surface temperatures on the electrical resistance elements varied between $92^{\circ} \mathrm{C}$ and $97^{\circ} \mathrm{C}$. Both tanks received water from the same feed-water line connected to the municipal main water supply of Johannesburg. Upstream of each tank a water meter and a flow meterwere installed. The watermeter was of the positive displacement type that could measure the volume of water used with an error of $\pm 2 \%$. The flowmeter was a rotameter that could measure the flow rate with an error of $\pm 4 \%$ at full scale. When the water was drained, the water temperature was measured in the water stream with a K-type thermocouple. The thermocouple was calibrated to an accuracy of $\pm 0.1^{\circ} \mathrm{C}$. All the tubes to and from the storage tanks were $22 \mathrm{~mm}$ (ID) copper tubes, which were soft-soldered in position. The wall thickness of the tubes was $0.5 \mathrm{~mm}$.

Upstream of each storage tank the distance to the position (when installed with cable ties) of the physical water treatment device was $2 \mathrm{~m}$. When installed, the length, width and height of the device when clamped into position were $128 \mathrm{~mm}, 66 \mathrm{~mm}$, and $32 \mathrm{~mm}$ respectively.

The maximum measured field strength of the physical water treatment device was $129 \mathrm{mT}$ (milli-Tesla). Measurements were made with a digital teslameter with an error of $\pm 2 \%$ in a constant magnetic field between $10^{-5}$ and $1 \mathrm{~T}$. The field strength distribution was measured on the centre line while the two halves of the magnet were clamped $23 \mathrm{~mm}$ from each other onto a similar copper tube used for the feed-water line. The measured field strength distributions are given in Figs. 3 and 4. In Fig. 3 the field strength is a negative value
Figure 2

Schematic representation of the experimental set-up

on the right side of the centre of the pipe. The reason is that the magnetic field lines change direction in this multi-pole unit with a south-north-north-south configuration, shown schematically in Fig. 1. For this configuration, the measurements along the magnet's length (Fig. 4) on the centre line on levels DD, EE and FF, should be zero because the magnetic field changes direction as the polarity changes. This is not the case, which indicates that the tube was not exactly in the centre of the magnet. It is, however, evident from these measurements, that the magnetic field lines change direction through the length of this unit. This implies that the polarity of the magnet also changes lengthwise. Since the field lines change direction across the width and length of the magnet it can be described as a multi-pole, multi-axial unit.

The manufacturers of the physical water treatment device made four recommendations on the installation of the device, which were followed carefully: the device should be clamped onto the feedwater line as indicated in Fig. 1; the flow direction through the tube should be in the same direction as indicated with an arrow on the device; the power cells should be installed in pairs where the number of pairs is determined by the size of the pipe diameter; lastly, the device should be installed $2 \mathrm{~m}$ to $3 \mathrm{~m}$ upstream of the storage tank.

\section{Test procedure}

Before any experiments were conducted, the tanks were cleaned with a $10 \%$ acetic acid solution. The solution was drained from the tanks and rinsed with $1000 \ell$ of feed water. The hot-water storage tanks were simultaneously filled with water from the feed-water line at a flow rate that ensured an average velocity of $1.75 \mathrm{~m} / \mathrm{s}$ in the tubes. One water sample was taken from the feed-water line three times a week to monitor the water quality. The instrumentation used for measuring the water quality parameters for each experiment is listed in Table 1. After every $12 \mathrm{~h}, 200 \ell$ of water was drained from each tank, again at a flow rate ensuring an average of $1.75 \mathrm{~m} / \mathrm{s}$ flow velocity through the tubes. This was repeated for a period of $28 \mathrm{~d}(672 \mathrm{~h})$, heating a total of $8000 \ell$ of water in each storage tank (during the weekends the water was not drained from the tanks). The scale on the electrical elements and on the inside walls of the storage tanks was stripped with a fresh $200 \ell, 10 \%$ acetic acid solution. Samples were taken every half an hour at the outlet of each storage tank whereafter the maximum concentration of calcium content was measured. 


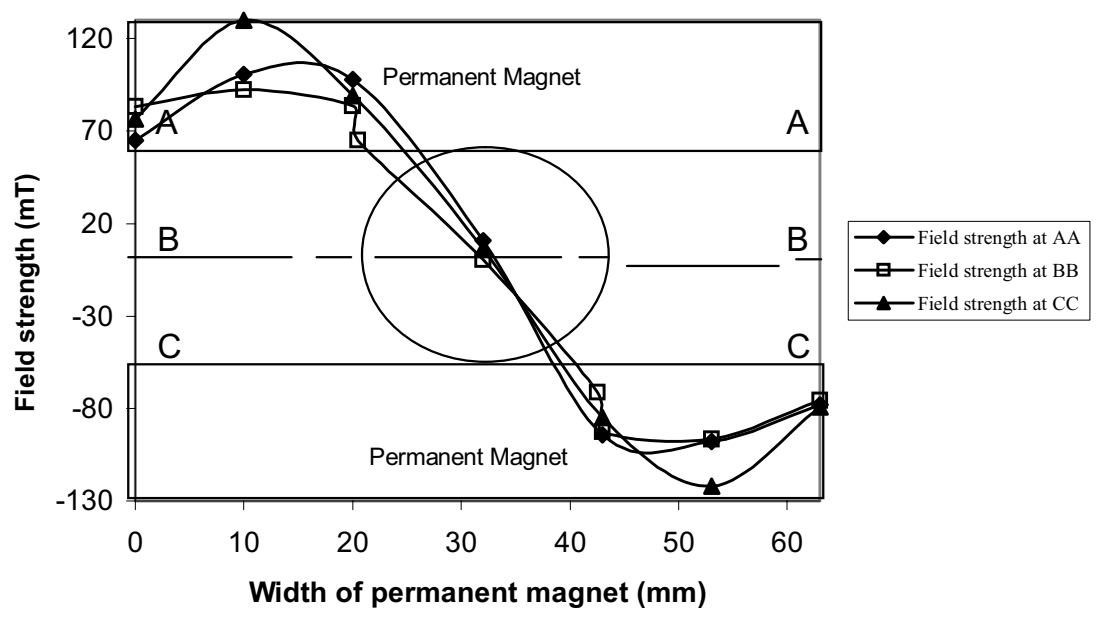

Figure 3

Measured field strength across and outside the tube over three sections (The orientation of the magnet relative to the tube is also shown)

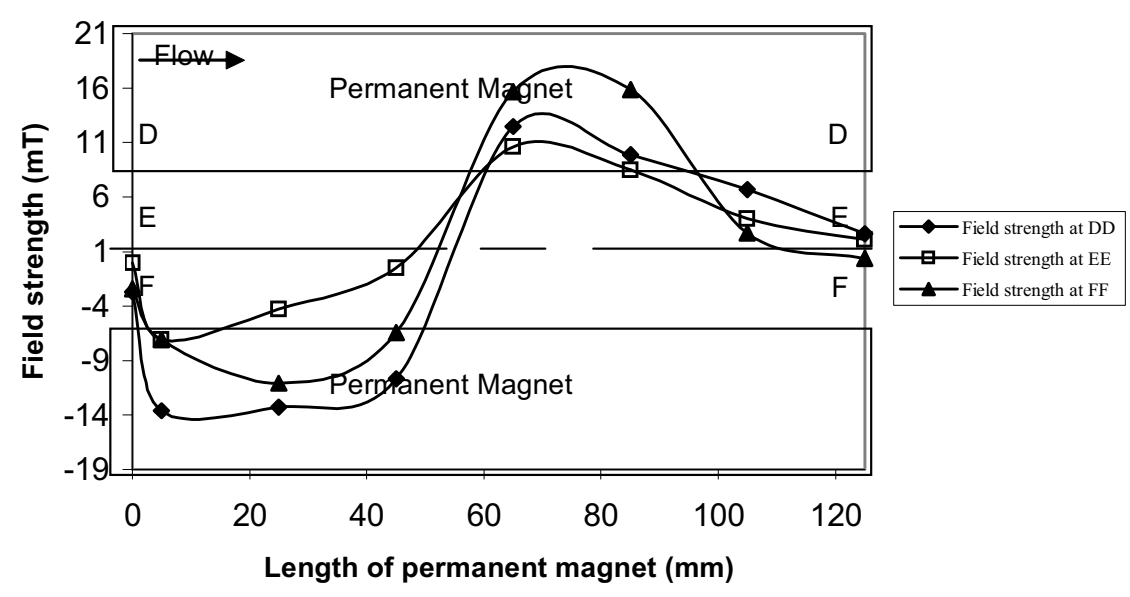

Figure 4

Measured field strength in the flow direction on three sections including the tube centre line (The orientation of the magnet relative to the tube is also shown) the other storage tank had no device and was used as control. In experiment 7 the experiment was again conducted without any device on either of the two tanks to verify reproducibility. In experiments 8 to10 the physical water treatment device was again commuted between the two storage tanks.

\section{Results and discussion}

The average water quality parameters represented by calcium and zinc concentration, alkalinity, $\mathrm{pH}$, and $\mathrm{pH}_{\mathrm{s}}$ (saturation $\mathrm{pH}$ ), and conductivity, are given in Figs. 5 to 7 for each experiment. In Figs. 8 and 9 the Langelier Saturation Index (Langelier, 1936) and Ryznar Stability Index (Ryznar, 1944) are also given. These indexes can be useful tools (ASHRAE, 1999) for predicting the calcium carbonate scaling tendency of the feed water.

All measurements of the water quality parameters were done at $\pm 25^{\circ} \mathrm{C}$, except the conductivity values, which were measured at $\pm 75^{\circ} \mathrm{C}$ and were used to calculate the Langelier and Ryznar indexes. Barring the calcium concentration in the feed water during experiment 3 , the average concentration of calcium in the feed water stayed approximately constant throughout the evaluation period of the permanent magnet, as illustrated in Fig. 5. Figure 5 also shows how the concentration of zinc changed in the feed water. Figure 6 shows the changes in the $\mathrm{pH}$ of the feed water. It is important to note that the $\mathrm{pH}$ was never higher than 8.8 , which would have increased the solubility of calcium carbonate in the water and decreased the formation of scale. Figure 6 also shows the saturation $\mathrm{pH}$ of the water inside the storage tanks at operating temperatures. The saturation $\mathrm{pH}$ was calculated after measuring the conductivity inside the tanks also at operating temperatures. Figure 6 shows that there were also no significant changes in the alkalinity during experimentation with a maximum of $8 \%$ deviation from the average alkalinity, measured as the concentration $\mathrm{CaCO}_{3}$ in the feed water. The conductivity is an indication of the total dissolved solids in the feed water. The higher this value the more likely it is that scale formation will occur. The conductivity values are illustrated in Fig. 7 and varied between 24.5 and 26.8 $\mu \mathrm{S} / \mathrm{m}$. The variation in the conductivity of the feed water was therefore small. Figures 8 and 9 illustrate the Langelier and Ryznar indexes for both the feed water and the heated water inside the storage tanks. The Langelier index is the numeric difference between the actual $\mathrm{pH}$ and the saturation $\mathrm{pH}\left(\mathrm{pH}-\mathrm{pH}_{\mathrm{s}}\right)$ where a positive value would indicate a scaling tendency and a negative value a corrosion tendency of the water. The Ryznar index is the numeric difference between twice the saturation $\mathrm{pH}$ and the actual $\mathrm{pH}\left(2 \mathrm{pH}_{\mathrm{s}}-\mathrm{pH}\right)$ where a value below six indicates a scaling tendency and a value above six a corrosion tendency of the feed water. The Langelier index shows that the feed water had a corrosion tendency for all the experiments. 


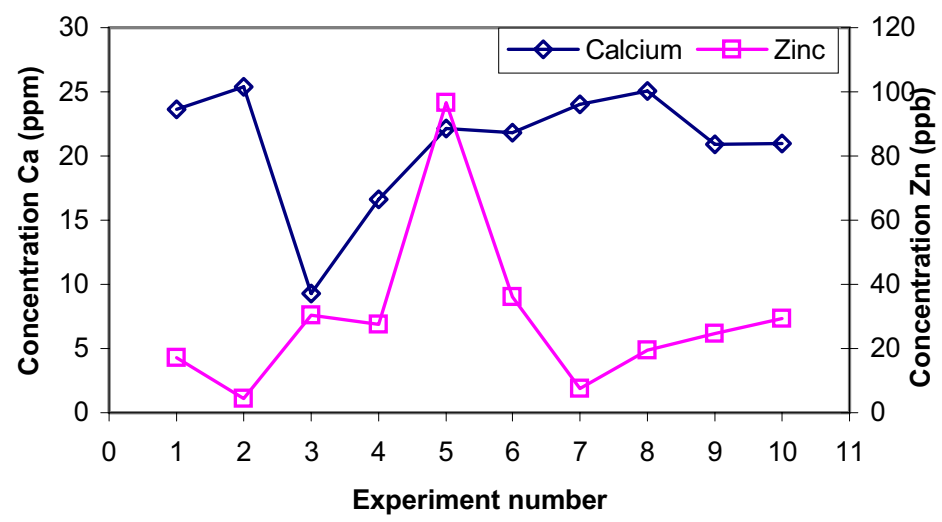

Figure 5

Average calcium and zinc concentration of the feed water during each experiment

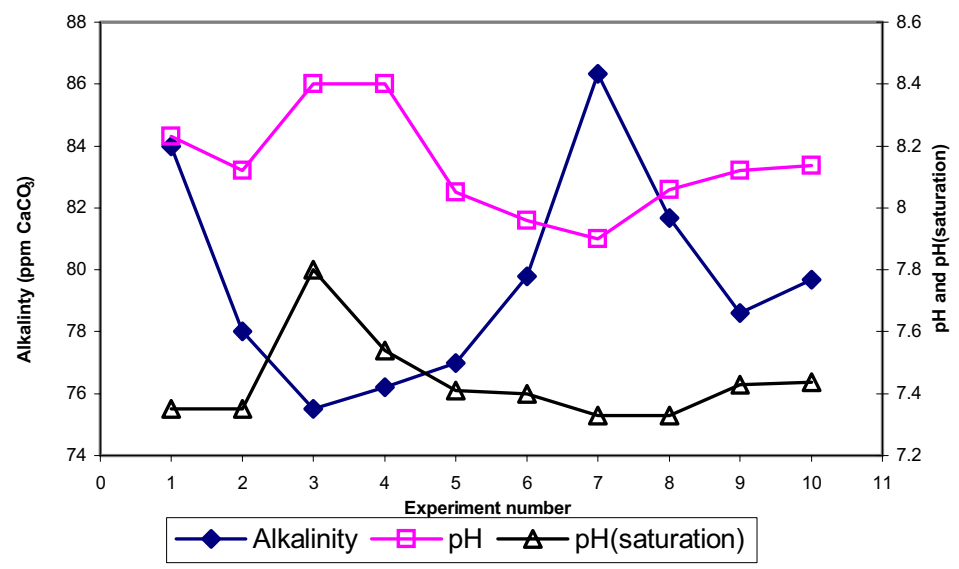

Figure 6

Average alkalinity, $\mathrm{pH}, \mathrm{pH}$ (saturation) of the feed water during each experiment

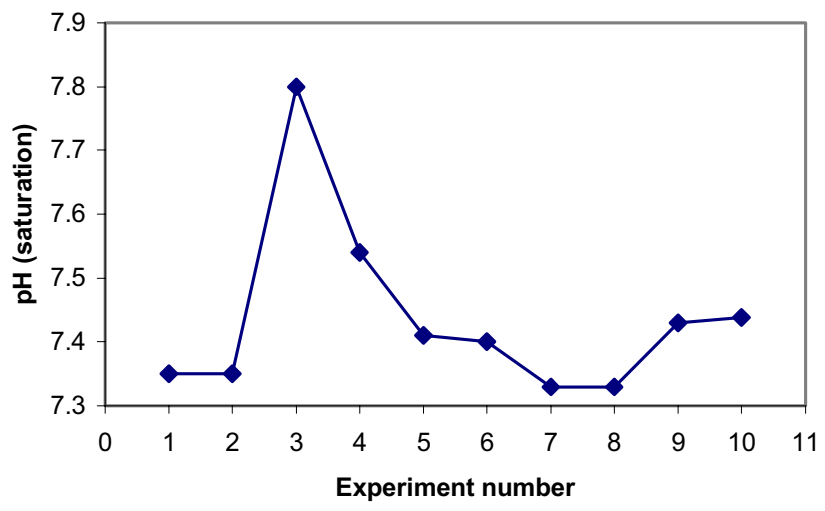

Figure 7

Average conductivity of the feed water during each experiment

The heated water inside the storage tanks, however, had a slight scaling tendency. This is due to the fact that the conductivity increases with an increase in temperature, which lowers the saturation $\mathrm{pH}$ and therefore enlarges the Langelier index value. The Ryznar index also shows that the feed water had a corrosion tendency during each experiment but by heating the water the Ryznar index value dropped to an average of 6.7. This indicates that the water was almost neutral (six being a neutral value for the Ryznar index which indicates that the water had neither a scaling tendency nor a corrosive nature).

The total mass of calcium precipitated on the inside wall of each hot-water storage tank together with the mass of calcium precipitated on its heating element for each experiment is shown in Fig. 10. The positions of the physical water treatment device for each experiment are also shown. The difference in mass of calcium precipitated in the two storage tanks during first three experiments is relatively small. The differences were $1.3 \%$ (experiment 1 ), $5.2 \%$ (experiment 2 ) and $0.42 \%$ (experiment 3 ) from the average between the two tanks. The average difference is thus $2.3 \%$. The largest difference between the two tanks is $5.2 \%$ for experiment 2 . No physical water treatment device was used during these experiments, as the objective of the first three experiments was to compare the reproducibility of the measurements made in the two storage tanks. It was concluded that the reproducibility of these experiments was acceptable.

In experiment 4 the physical water treatment device was installed for the first time (on the feed-water line of storage tank 2). The mass of calcium precipitated in this tank was measured as $70 \%$ less than for the tank without the physical water treatment device. In experiments 5 and 6 the device was commuted between the two tanks. The amount of scale formed was less in the tanks containing the physical water treatment device (33\% and $31 \%$ less respectively for experiments 5 and 6).

In experiment 7 no device was used on either one of the tanks. The mass of calcium precipitated in the two tanks differed by $8 \%$. This was larger than the average of the first three experiments of $2.3 \%$. However, the mass of calcium measured in each tank was low, which could contribute to a relatively larger measuring error. Therefore, on average if the physical water treatment device was not used, the mass of precipitated calcium in the two storage tanks differed by only $3.7 \%$. Reproducibility was therefore good.

In experiment 8 the device was again installed onto storage tank 1 and commuted between the two tanks in experiments 9 and 10. In each case where the physical water treatment device was used, less calcium precipitated in the storage tank than in the control tank (i.e. $17 \%, 17 \%$ and $32 \%$ less calcium respectively for experiments $8,9$ and 10$)$.

From Fig. 10 it can be seen that the mass of precipitated calcium drastically decreased after the first two experiments. One possible reason for this is that small amounts of some metal ions, in particular $\mathrm{Zn}^{2+}$ ions, can reduce the nucleation rate of calcium carbonate crystallisation (Coetzee, 1998). In addition the predominant crystal structure of the calcium carbonate formed changed to aragonite instead of calcite. Both these effects can lead to less scale formation. If the concentrations of zinc are compared for the respective experiments (shown in Fig. 10), experiments 1 and 2 showed the lowest values of this scale-inhibiting metal ion, which were $7 \mu \mathrm{g} \cdot \ell^{-1}$ and $5 \mu \mathrm{g} \cdot \ell^{-1}$ respectively. For experiment 2 with the highest mass of precipitated scale the concentration of $\mathrm{Zn}^{2+}$ ions was at its minimum. Another possible reason for the receding trend of precipitated scale might be the characteristics of the feed water quality as indicated by the Langelier and Ryznar indexes (Figs. 8 and 9). The line fitted through the data of Fig. 8 exhibits a receding trend. The declining values on the Langelier index indicate that the 
water's scale-forming ability is declining and water tends to be more neutral (neither scale-forming nor corrosive). The line fitted through the Ryznar index in Fig. 9 exhibits a very slight inclining trend.

On average, for the six times that the device was used, $36 \%$ less calcium carbonate precipitated than in the control tank which was run without any device. It can therefore be deduced that the physical water treatment device that was tested, reduced calcium carbonate precipitation over the period that the experiments were conducted.

It was also observed visually after experiment 4 , as shown in Figs. 11 and 12, that the electrical resistance element of the storage tank where the physical water treatment device was used, was still shiny with almost no deposits adhering to the surface whereas the electrical resistance element operated without any device had a matt appearance with obvious deposits adhering to the surface. Precipitates from each electrical element were studied with scanning electron microscopy. No morphological differences in the crystals between tests and controls could be observed. Investigating morphological changes was difficult as only very small pieces of deposit could be removed from the electrical heating elements. The reason for this is that the difference in weight of the precipitated scale on each element was small and removing some of these precipitates would influence the results when the different masses of precipitated scale on the elements were compared.

\section{Summary and conclusion}

The study of physical water treatment devices is a controversial subject with results ranging from total success to total failure. The effectiveness of these devices is met with scepticism by researchers and industry alike. The reason for this is the low reproducibility of results and the absence of a plausible mechanism to explain the working of the physical water treatment devices.

During this study an experimental set-up was built and experiments were conducted on two hot-water storage tanks following a very simple experimental procedure which gave reproducible results. Experiments without the permanent magnet showed an average of $3.7 \%$ difference from the average amount of calcium precipitation between the storage tanks while the use of the permanent magnet reduced the formation of scale in the hot-water storage tanks with an average of $34 \%$. The maximum reduction in scale formation was $70 \%$ and the minimum $17 \%$.

\section{Acknowledgements}

This work was financially supported by the WRC.

\section{References}

ASHRAE (1999) ASHRAE Handbook, HVAC Applications, American Society of Heating, Refrigerating and Air-Conditioning Engineers, Atlanta, GA.

BAKER JS and JUDD SJ (1996) Magnetic amelioration of scale formation. Water Res. 30 (2) 247-260.

BUSCH KW, BUSCH MA, PARKER DH, DARLING RE and MCATEE JL (Jr.) (1986) Studies of water treatment devices that use magnetic fields. Corrosion 42 (4) 211-221.

CHAN SH and GHASSEMI KF (1991) Analytical modeling of calcium carbonate deposition for laminar falling films and

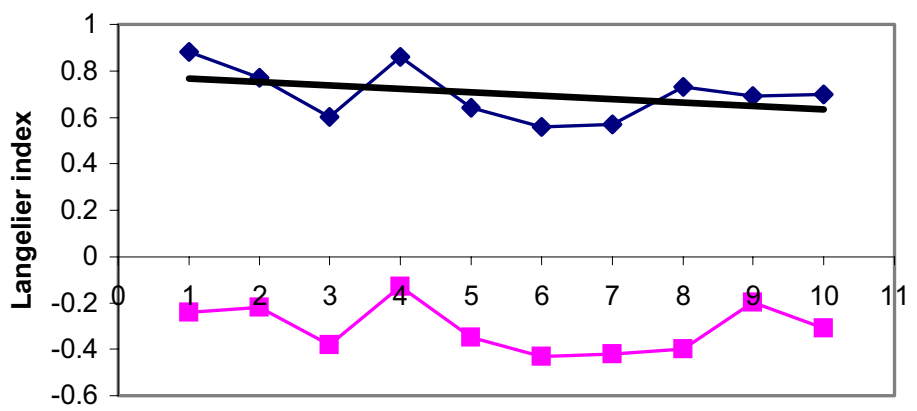

Experiment number

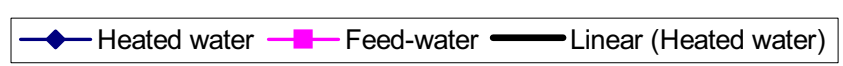

Figure 8

Langelier Saturation Index for the duration of each experiment

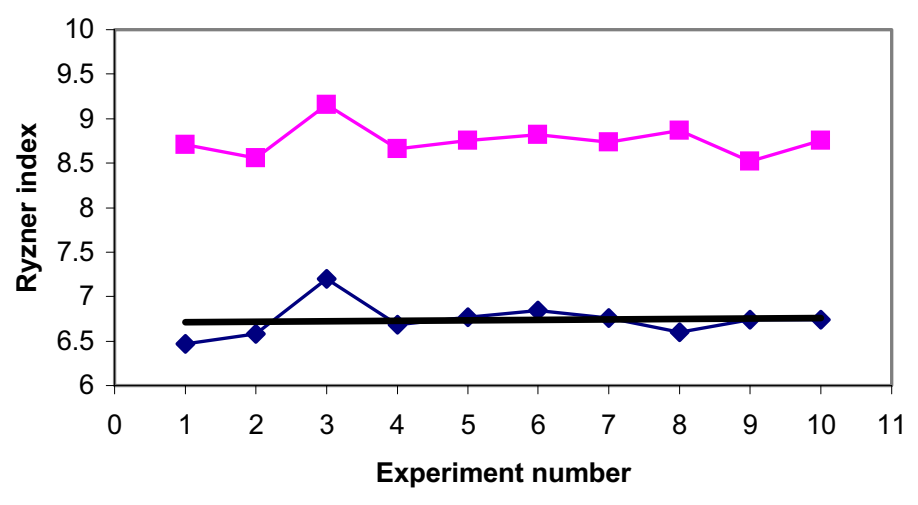

Heated water $\longrightarrow$ - Feed-water $\longrightarrow$ Linear (Heated water)

Figure 9

Ryznar Stability Index for the duration of each experiment

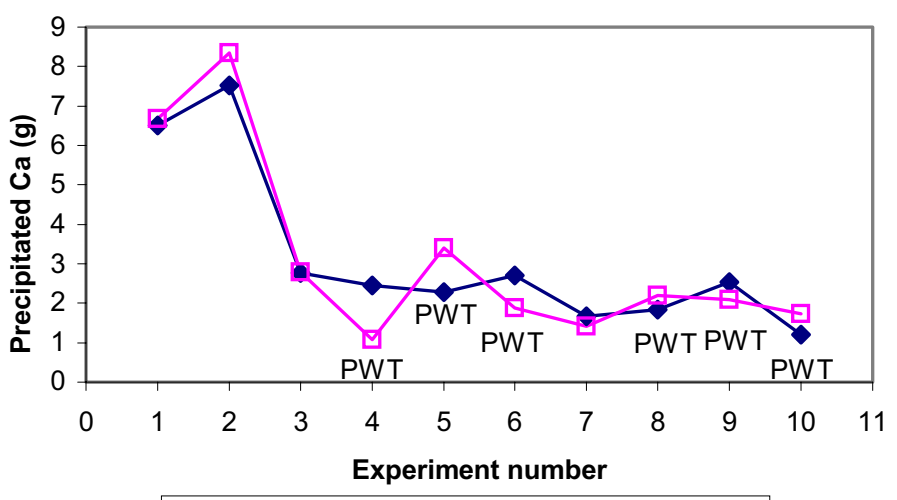

Storage tank no.1 $\square$ Storage tank no.2

Figure 10

Mass of precipitated calcium in the storage tanks and the position of the physical water treatment device (PWT)

turbulent flow in annuli: Part I-Formulation and single-Species model. J. Heat Transfer 113 735-746.

COETZEE PP, YACOBY M, HOWELL S and MUBENGA S (1998) Scale reduction and scale modification effects induced by $\mathrm{Zn}$ and other metals species in physical water treatment. Water SA 24 77-84. 


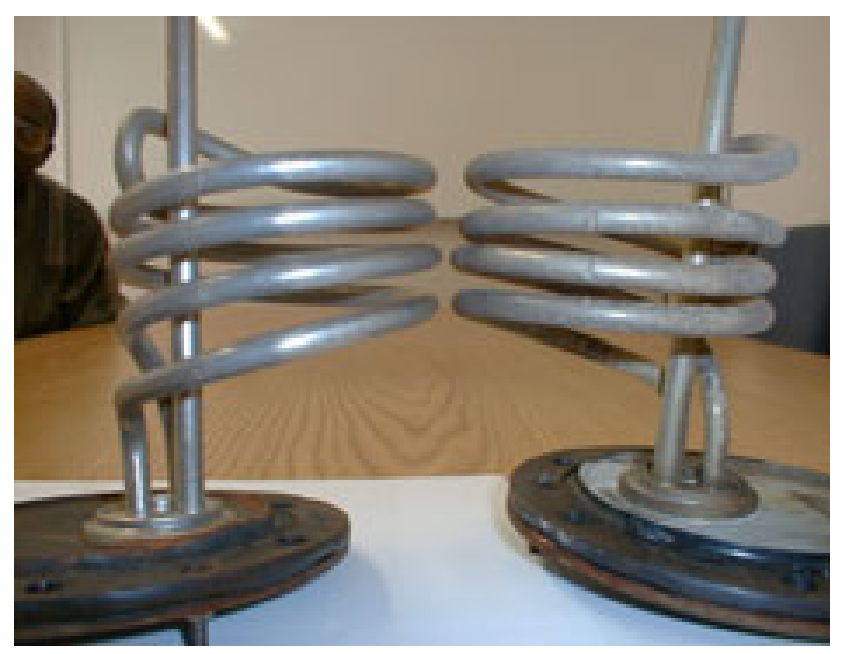

Figure 11

Photograph showing the precipitation on the electrical resistance elements of the two storage tanks. The physical water treatment device was on the system to the left in the photograph.

DARVILL M (1993) Magnetic water treatment. Water Waste Treat. (July) 40 pp.

GLATER J, YORK JL and CAMPBELL KS (1980) Scale formation and prevention. In: Spiegler KS and Laird ADK (eds.) Principles of Desalination Part B ( $2^{\text {nd }}$ edn.). Academic Press, New York. $627-$ 678.

GRUTSCH JF and McCLINTOCK JW (1984) Corrosion and deposit control in alkaline cooling water using magnetic water treatment at Amoco's largest refinery. Paper No. 330, Corrosion 84. National Association of Corrosion Engineers, New Orleans.

LANGERIER WF (1936) The analytical control of anticorrosion water treatment. J. AWWA. 28 1500-1521.

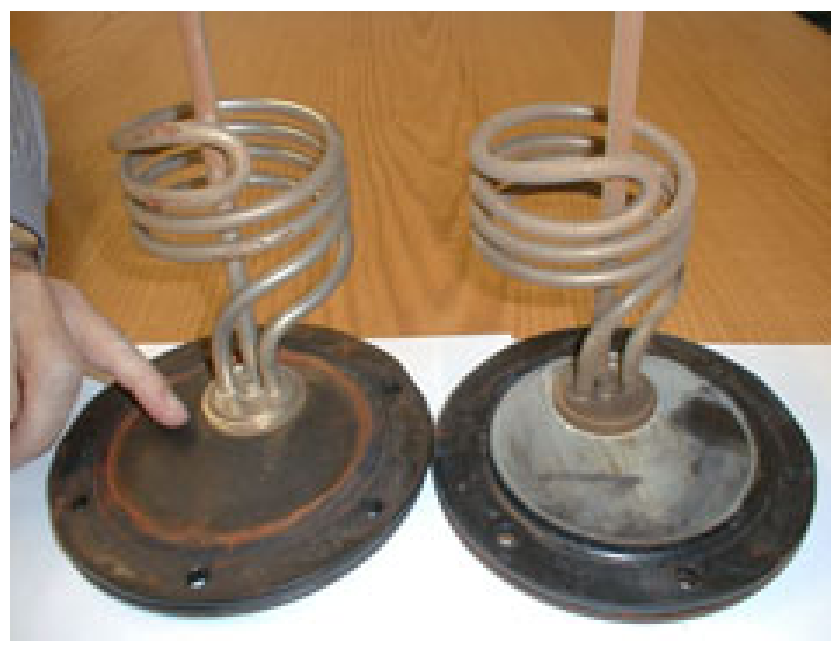

Figure 12

Photograph showing the precipitation on the base of the electrical resistance elements. The physical water treatment device was installed on the system to the left in the photograph.

MEYER HJ (1984) The influence of impurities on the growth rate of calcite. J. Crystal Growth 66 639-646.

RYZNAR JW (1944) A new index for determining amount of calcium carbonate scale formed by a water. J. AWWA. 36 472-486.

VERMEIREN T (1958) Magnetic treatment of liquids for scale and corrosion prevention. Corrosion Technol. 215-219.

YACOBY MJ (1995) The Effect of Magnetic and Constant Electric Field Antiscaling Devices on the Mechanism of $\mathrm{CaCO}_{3}$ Scale Formation. MSc Dissertation, Rand Afrikaans Univ., Johannesburg. 